\title{
Cytogenetics and sperm ultrastructure of Atelopus spumarius (Anura, Bufonidae) from the Brazilian Amazon
}

\author{
Sérgio Siqueira ${ }^{1,2}$, Odair Aguiar Junior ${ }^{3}$, Albertina Pimentel Lima ${ }^{4}$ and Shirlei Maria Recco-Pimentel ${ }^{1}$ \\ ${ }^{1}$ Departamento de Biologia Estrutural e Funcional, Instituto de Biologia, \\ Universidade Estadual de Campinas, Campinas, SP, Brazil. \\ ${ }^{2}$ Departamento de Ciências Biológicas, Universidade Estadual do Sudoeste da Bahia, Jequié, BA, Brazil. \\ ${ }^{3}$ Departamento de Biociências, Universidade Federal de São Paulo, Santos, SP, Brazil. \\ ${ }^{4}$ Coordenadoria de Pesquisa em Ecologia, Instituto Nacional de Pesquisas da Amazônia, \\ Manaus, AM, Brazil.
}

\begin{abstract}
The current taxonomy of most Atelopus species is based on morphological and color data only. Recent studies suggest that $A$. spumarius may represent a species complex assigned under the same name. Karyotypic data and description of sperm ultrastructure for 13 specimens of $A$. spumarius are presented here for the first time. A chromosomal analysis revealed $2 n=22$ chromosomes, with centromeric heterochromatin in all pairs and a nucleolar organizer region (NOR) on the telomere of pair 7 . The sperm was of the bufonoid type, presenting a filiform nucleus covered by an acrosomal complex and a mitochondrial collar in the neck region. The tail was composed of an axoneme, an undulating membrane and an axial rod. A karyotype analysis of $A$. spumarius showed the same chromosome number and similar chromosomal morphology as described for congeneric species, with slight differences probably resulting from pericentric inversions. The NOR location (on pair 7) was the same as that observed for species belonging to the genus Rhinella. The spermatological findings indicate a close relationship between Atelopus and the bufonoid lineage. The present data are useful for reference in future studies to determine whether more than one species are assigned to $A$. spumarius.
\end{abstract}

Keywords: Ag-NOR, Atelopus spumarius, C-band, chromosome, sperm ultrastructure.

Received: April 1, 2013; Accepted: June 20, 2013.

The harlequin frog, Atelopus spumarius Cope, 1871, is found in the Amazon region throughout Ecuador, Peru, the Guianas and Brazil (Amazonas, Para and Amapá states) (Frost, 2013). Cocroft et al. (1990) and Lötters et al. (2002) suggested that this name may refer to a species complex, with the true $A$. spumarius being found only in the upper Amazon Basin (Peru, Colombia and Brazil). This suggestion implies that the populations in southern Peru, Ecuador and central Brazil may represent undescribed taxa. Furthermore, Lötters et al. (2002) suggested that the populations from Guiana and the eastern Amazon may belong to yet another species complex: Atelopus hoogmoedi.

The current taxonomy of this genus is solely based on morphological and color data (Ramos et al., 2002), with the presence of toxins also being considered a taxonomic tool (Kim et al., 1975). Other potentially useful criteria, such as osteology, larval morphology, molecular data, cytogenetics

Send correspondence to Shirlei M. Recco-Pimentel. Departamento de Biologia Estrutural e Funcional, Instituto de Biologia, Universidade Estadual de Campinas, 13083-863 Campinas, SP, Brazil. E-mail: shirlei@unicamp.br. and sperm ultrastructure, have not been applied to this genus. In anurans in general, cytogenetics has been used increasingly as a tool to investigate chromosomal evolution and to make taxonomic inferences, indicating the existence of new species and differentiating between cryptic ones (Giaretta and Aguiar-Jr 1998, Medeiros et al. 2003; Lourenço et al., 2006; Siqueira et al., 2008), and data from sperm ultrastructure have been used as additional characters in systematic studies (see Jamieson and Leung, 1991; Garda et al., 2002, Aguiar-Jr et al., 2006; Veiga-Menoncello et al. 2006, 2007).

The only cytogenetic studies in Atelopus done so far are those on A. varius (Duellman, 1967; Schmid, 1980), $A$. ignescens and A. guanujo (Barrera et al. 1984), and A. zeteki (Ramos et al., 2002), which described $2 \mathrm{n}=22$ chromosomes with highly similar morphology. No differential staining (C-banding or Ag-NOR) studies have been done in this genus. Sperm ultrastructure data are available for other genera in the family Bufonidae, but not for Atelopus. Species within the genera Ansonia, Bufo, Nimbaphrynoides and Melanophriniscus have been studied using sperm ultra- 
structure data (Jamieson, 2003) and show a morphological pattern that characterizes the superfamily Bufonoidea.

We present unique chromosomal data, including banding patterns, for $A$. spumarius and the first ultrastructural sperm characteristics for the genus Atelopus. Our aim was to expand the number of characteristics available for making taxonomic inferences in future studies.

Nine males and four females of $A$. spumarius from Reserva Florestal Adolpho Ducke, Manaus, Amazonas, were analyzed. The frogs were collected with the authorization of the Instituto Brasileiro do Meio Ambiente e Recursos Naturais Renováveis (IBAMA - Proc. 02010.000025/2005-51). Voucher specimens were deposited in the Museu de Zoologia "Prof. Adão José Cardoso" of Instituto de Biologia at Universidade Estadual de Campinas, Brazil, under the following accession numbers: 13274-13298.

Mitotic metaphases were obtained from testicular and intestinal epithelial cell suspensions, as described by King and Rofe (1976) and Schmid (1978). The chromosomes were stained with $10 \%$ Giemsa solution and subjected to C-banding (Sumner, 1972), with slight modifications as suggested by Siqueira et al. (2008), and to Ag-NOR (Howell and Black, 1980) techniques. All slides were analyzed with an Olympus BX60 microscope, and images were processed using Image Pro-Plus 5.1 software. The chromosomes of at least five metaphases were measured and classified as described by Green and Sessions (1991).

Testes were removed, cut into small pieces and fixed overnight at $4{ }^{\circ} \mathrm{C}$ in $0.1 \mathrm{M}$ sodium cacodylate buffer, $\mathrm{pH} 7.2$, containing $2 \%$ paraformaldehyde, $2 \%$ glutaraldehyde, $3 \%$ sucrose and $5 \mathrm{mM} \mathrm{CaCl}_{2}$. Postfixation was performed for $1 \mathrm{~h}$ in the same buffer containing $1 \%$ osmium tetroxide, $0.8 \%$ potassium ferricyanide and $5 \mathrm{mM}$ $\mathrm{CaCl}_{2}$. The tissues were subsequently rinsed in sodium cacodylate buffer and incubated en bloc with $0.5 \%$ uranyl acetate. After rinsing in buffer, the tissue fragments were dehydrated in an increasing ethanol series and embedded in Epon 812 resin. Ultrathin sections were stained with uranyl acetate and lead citrate (Watson, 1958; Venable and Coggeshall, 1965) and examined with a LEO 906 transmission electron microscope. Scanning electron microscopy was performed following the protocol of VeigaMenoncello et al. (2007).

Atelopus spumarius (Figure 1) presented a diploid number of 22 chromosomes; pairs 1, 2, 5-7 and 9-11 were metacentrics, and pairs 3, 4 and 8 were submetacentrics (Figure 2A-C). This species has the same chromosome number and chromosomal morphology similar to $A$. varius, A. zeteki, A. ignescens and A. guanujo (Duellman, 1967; Schmid, 1980; Barrera et al. 1984; Ramos et al., 2002). Pairs 8 and 9 have a very similar size, accounting for their inverted position when different karyotypes are compared. Such inverted position and some variation in chromosomal morphology between the karyotyped species may be due to

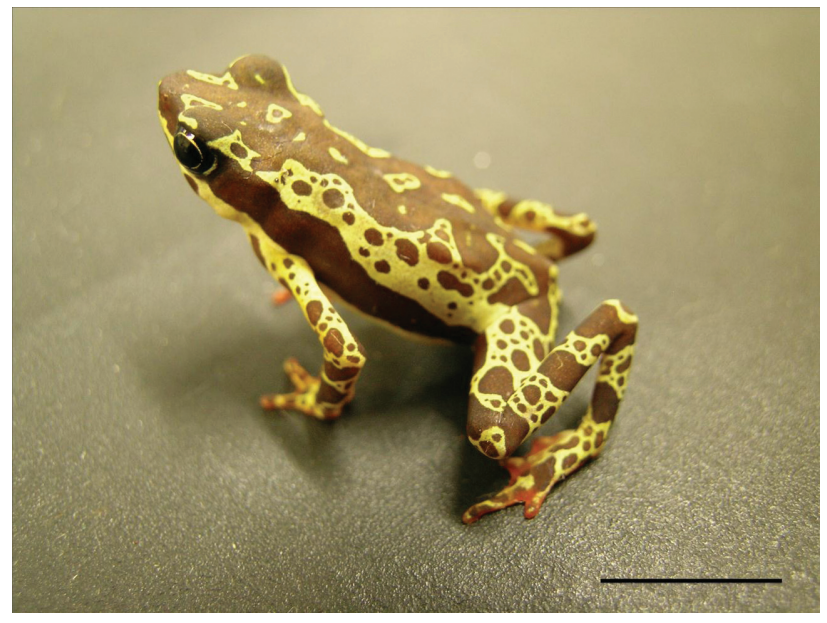

Figure 1 - Photograph of a specimen of Atelopus spumarius from Reserva Florestal Adolpho Ducke, Manaus, Amazonas. Photograph by S. Siqueira. Bar $=1 \mathrm{~cm}$.

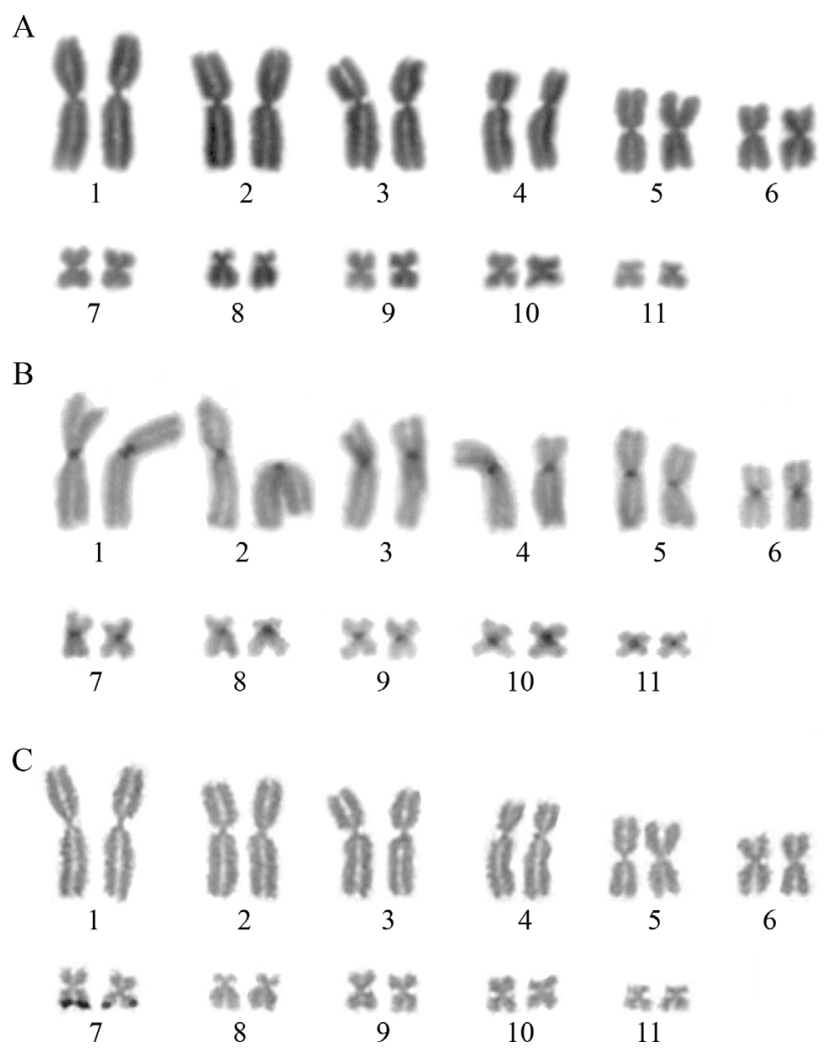

Figure 2 - Karyotypes of Atelopus spumarius subjected to: (A) Giemsa staining; (B) C-banding; (C) Ag-NOR staining. Note the telomeric NOR in the long arms of pair 7 (arrow).

pericentric inversions, a mechanism suggested for chromosomal evolution in Atelopus (Ramos et al., 2002).

According to Kuramoto (1990), the majority of Bufonidae species have $2 \mathrm{n}=22$ chromosomes, suggesting that chromosome number is highly conserved in this family. This assumption was corroborated by Bush et al. (1977), who postulate that the bufonids have a slow rate of 
chromosomal evolution in comparison with other vertebrate groups. This hypothesis is supported by karyotype analyses of other bufonid taxa, including Rhinella crucifer, $R$. icterica and R. schneideri (Kasahara et al., 1996), Melanophryniscus species (King, 1990; Kuramoto, 1990), and the species of the genus Bufo studied by Baldissera et al. (1999), whose karyotypes are very similar to each other and to those of Atelopus.

All the karyotypes described so far in this genus had only been analyzed by conventional Giemsa staining. The C-banding technique here employed detected heterochromatin only in the centromeres of all pairs (Figure 2B). The lack of C-banding patterns for other Atelopus species precludes intrageneric comparisons. Nonetheless, the patterns described here are very similar to those found for Chaunus species by Amaro-Ghilardi et al. (2008). The shared centromeric-pericentromeric banding pattern in these species reinforces the idea of a conserved karyotypic nature of this pattern, but the significance of such similarity cannot be assessed until the evolutionary state of such character (heterochromatin distribution) is defined.

NOR regions were detected on the telomeres of the long arm of pair 7 (Figure 2C). In A. zeteki (Ramos et al., 2002), the pericentromeric constriction observed in pair 7 is probably the NOR site, which coincides with the location found in A. spumarius.

On the basis of studies of NOR location, Baldissera et al. (1999) found three groups within six Bufo species analyzed. The first two groups were composed of species with Ag-NOR labeling on pair 5 and/or 10 (B. arenarium, $B$. rufus, $B$. ictericus and B. paracnemis). The third group included B. marinus and B. crucifer, where NORs were located on pair 7, which is characteristic of the crucifer and marinus groups. The last two species (B. ictericus and $B$. paracnemis) were later separated from the other Bufo species and included in the new genus Rhinella (Chaparro et al., 2007; Frost, 2013) The shared presence of a NOR in pair 7 could indicate a degree of proximity between these taxa and the Atelopus species.

Under scanning electron microscopy, the spermatozoon of Atelopus spumarius presented a $19 \mu \mathrm{m}$ long filiform head and a $40 \mu \mathrm{m}$ long tail. The tail had a very large undulating membrane (Figure 3A). In longitudinal sections the nucleus appeared cylindrical, with the anterior portion covered by the acrosomal complex (Figure 3B). The acrosome consists of a conical electron-dense vesicle covering $6 \mu \mathrm{m}$ of the anterior portion of the nucleus.

A subacrosomal cone filled with a diffuse, thick material is observed under the acrosome (Figure 3B). In transverse sections the acrosomal complex appeared circular and became progressively narrower posteriorly, together with the subacrosomal cone (Figure 3D-H). Also in these sections the nucleus appeared circular with a $0.9 \mu \mathrm{m}$ width at its base (Fig. 3I). The chromatin was highly electron dense and had a fibrillar-like structure, with differentially condensed areas (Figure 3H-J).

The features of the acrosomal complex here observed (i.e., the nucleus covered by an acrosomal vesicle above the subacrosomal cone) are characteristic of the neobatrachian bufonoid lineage and have been described for most species of the previous genus Bufo (Jamieson, 2003).

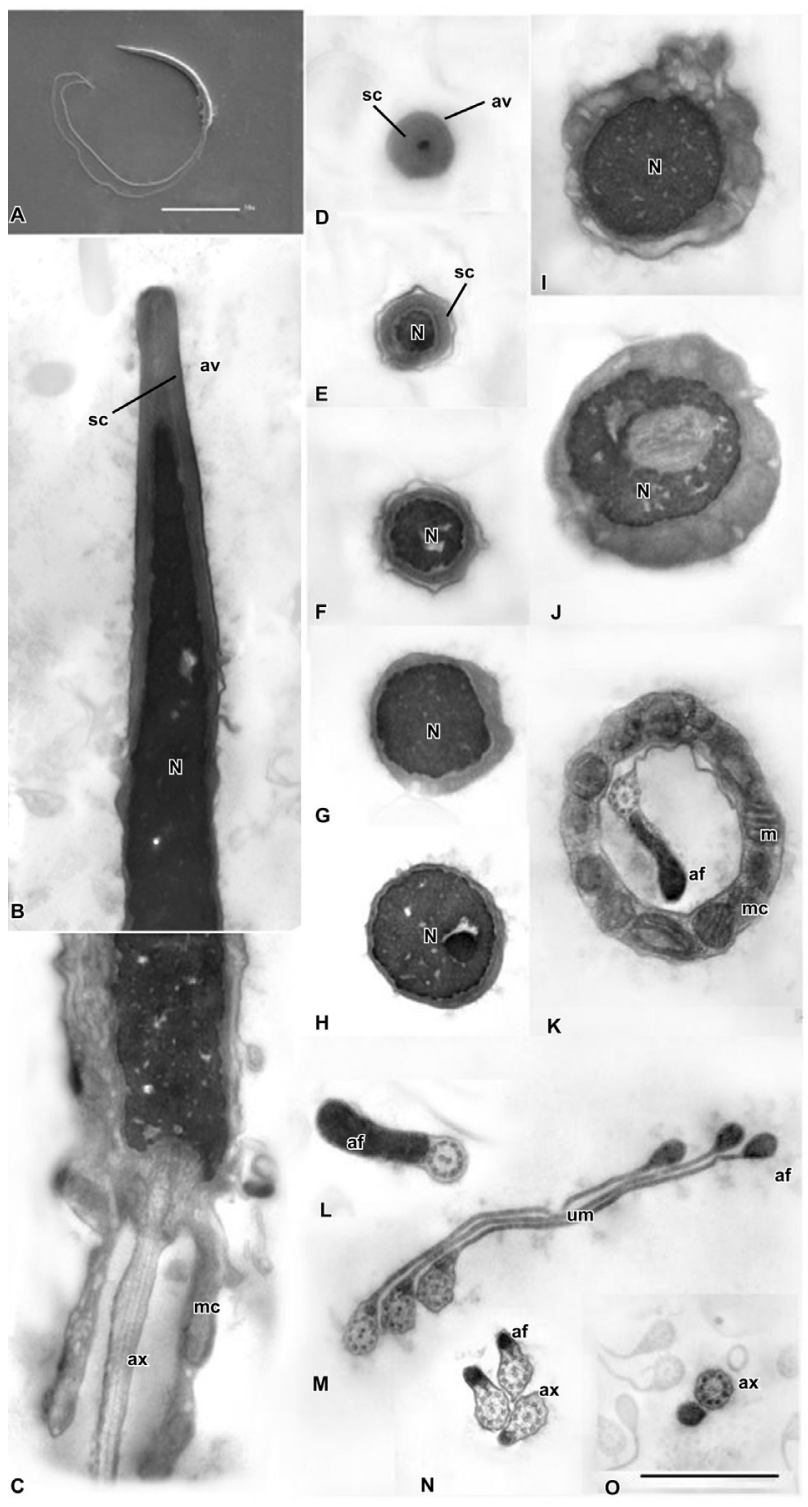

Figure 3 - Spermatozoa of Atelopus spumarius. Scanning (A) and transmission (B-O) electron micrographs. B and C: longitudinal sections of the head and flagellum, respectively. In B, note the acrosomal complex, with the acrosomal vesicle (av) and the subacrosomal cone (sc), covering the nucleus. D-H: transverse sections of the head showing the circular shape of the acrosomal complex. I and $\mathrm{J}$ : basal region of the nucleus showing the nucleus $(\mathrm{N})$ with fibrillar-like chromatin. $\mathrm{K}$ : mitochondrial collar $(\mathrm{mc})$ surrounding the initial portion of the flagellum. L-O: transverse sections of the flagellum, showing the axial fiber (af) and undulating membrane (um) $(\mathrm{L}$ and $\mathrm{M})$, which become closer in the distal portion $(\mathrm{N})$ until only the axoneme (ax) is observed in the final portion (O). Bar $=1 \mu \mathrm{m} . \mathrm{Bar}=10 \mu \mathrm{m}$ (A), $1 \mu \mathrm{m}(\mathrm{B}-\mathrm{O})$. 
In the midpiece, a nuclear fossa contained the proximal and distal centrioles, which lie at an angle of $90^{\circ}$ to each other (Figure 3C). The axoneme originates from the distal centriole. A cytoplasmic expansion containing mitochondria extended from the nuclear base to the initial portion of the flagellum, forming a collar-like structure also observed in transverse sections (Figure $3 \mathrm{C}$ and $\mathrm{K}$ ).

In transverse sections, the flagellum consisted of an axoneme, an undulating membrane and a highly electrondense axial fiber with a width similar to that of the axoneme (Figure $3 \mathrm{~K}$ and $\mathrm{L}$ ). The axoneme and axial fiber merge in the distal portion of the tail (Figure 3M). The fiber appeared as a protein bridge that narrows at the final portion of the tail (Figure 3N). In the distal portion of the flagellum, the axial fiber became closer to the axoneme and then disappeared together with the undulating membrane (Figure $3 \mathrm{~N}$ ). At the end of the flagellum, only the axoneme was observed (Figure 3O).

The spermatological patterns of the flagellum (i.e., composed of an axoneme and axial rod, presence of a mitochondrial collar and undulating membrane) are also characteristic of the neobatrachian bufonoid lineage, as found by Jamieson (2003) in most species of the previous genus Bufo.

Using molecular data, Grant et al. (2006) presented a cladogram indicating as the Atelopus sister groups the genus Melanoprhyniscus and the three genera now included in the family Hylodidae (Hylodes, Crossodactylus and Megaelosia). These proposed relationships are supported by the present data, as Melanophryniscus cambaraensis (Báo et al., 2001) and the hylodids Hylodes phyllodes, Crossodactylus sp. and Megaelosia massarti display the same sperm ultrastructural pattern observed in $A$. spumarius.

Taken together, the sperm ultrastructural characteristics of A. spumarius and the karyotype data support its close proximity to the bufonoid lineage.

The present findings better characterized the species Atelopus spumarius and allow future comparative studies to determine whether more than one species is assigned under this name. The unique C-banding, Ag-NOR and ultrastructural data of $A$. spumarius corroborate its position within the family Bufonidae. In addition, the numerically and morphologically conserved karyotypes within Atelopus species studied so far attest to the well-documented monophyly postulated by Lötters et al. (2010).

\section{Acknowledgments}

The authors thank Mary Anne Heidi Dolder for access to the laboratory facilities for ultrathin sectioning. This research was supported by the Coordenação de Aperfeiçoamento de Pessoal de Nível Superior (CAPES, PROEX and a scholarship to S. Siqueira) and Fundação de Amparo à Pesquisa do Estado de São Paulo (FAPESP, grant 06/61738-3).

\section{References}

Aguiar-Jr O, Giaretta AA and Recco-Pimentel SM (2006) The sperm of Hylodinae species (Anura Leptodactylidae): Ultrastructural characteristics and their relevance to interspecific taxonomic relationships. J Biosci 31:379-388.

Amaro-Ghilardi RC, Silva MJJ, Rodrigues MT and YonenagaYassuda Y (2008) Chromosomal studies in four species of genus Chaunus (Bufonidae, Anura): Localization of telomeric and ribosomal sequences after fluorescence in situ hybridization (FISH). Genetica 134:159-168.

Baldissera FA, Batistic RF and Haddad CFB (1999) Cytotaxonomic considerations with the description of two new NOR locations for South American toads, genus Bufo (Anura, Bufonidae). Amphibia-Reptilia 20:413-420.

Báo SN, Vieira GH and Fernandes AP (2001) Spermiogenesis in Melanophryniscus ambaraensis (Amphibia, Anura, Bufonidae): Ultrastructural and cytochemical studies of carbohydrates using lectins. Cytobios 106:203-216.

Barrera AM, Lobato L and Araujo B (1984) Estudio cromosómico dos especies de Anura (Hylidae-Bufonidae). Soc Ecuador Biol, VIII Jord Nac Cienc Biol "Gustavo Orcés V" 2:419427.

Bush GL, Case SM, Wilson AC and Patton JL (1977) Rapid speciation and chromosomal evolution in mammals. Proc Natl Acad Sci USA 74:3942-3946.

Chaparro JC, Pramuk JB and Gluesenkamp AB (2007) A new species of arboreal Rhinella (Anura, Bufonidae) from a cloud forest of southeastern Peru. Herpetologica 63:203212.

Cocroft RB, McDiarmid RW, Jaslow AP and Ruiz-Carranza PM (1990) Vocalization of eight species of Atelopus (Anura, Bufonidae) with comments on the communication in the genus. Copeia 1990:631-643.

Duellman WE (1967) Additional studies of chromosome of anuran amphibiams. Syst Zool 16:38-43.

Garda AA, Colli GR, Aguiar-Jr O, Recco-Pimentel SM and Báo SN (2002) The ultrastructure of the spermatozoa of Epipedobates flavopictus (Dendrobatidae, Anura, Amphibia), with comments on its evolutionary significance. Tissue Cell 34:356-364.

Giaretta AA and Aguiar-Jr O (1998) A new species of Megaelosia from the Mantiqueira Range, Southeastern Brazil. J Herpet 32:80-83.

Grant T, Frost DR, Caldwell JP, Gagliardo R, Haddad CFB, Kok PJR, Means DB, Noonan BP, Schargel W and Wheeler WC (2006) Phylogenetic systematics of dart-poison frogs and their relatives (Amphibia, Athesphatanura, Dendrobatidae). Bull Am Mus Nat Hist 299:1-262.

Green MG and Sessions SK (1991) Nomenclature for chromosomes. In: Green DM and Sessions SK (eds) Amphibian Cytogenetics and Evolution. Acad Press, San Diego, pp 431-432.

Howell WM and Black DA (1980) Controlled silver-staining of nucleolus organizer regions with a protective colloidal developer: 1-step method. Experientia 36:1014-1015.

Jamieson BGM and Leung LKP (1991) Introduction to fish spermatozoa and the micropyle. In: Jamieson BGM and Leung LKP (eds) Fish Evolution and Systematics: Evidence from Spermatozoa. Cambridge Univ Press, Cambridge, pp 56-72.

Jamieson BGM (2003) Reproductive Biology and Phylogeny of Anura. Science Publishers Inc., Enfield, 450 pp. 
Kasahara S, Zampieri-Silva AP and Haddad CFB (1996) Chromosome banding in three species of Brazilian toads (Amphibia-Bufonidae). Braz J Genet 19:237-242.

Kim HY, Brown GB and Mosher H (1975) Tetrodotoxin: Ocurrence in Atelopid frogs of Costa Rica. Science 185:151-152.

King HY (1990) Animal cytogenetics. In: John B and Gwent C (eds) Chordata 2. Amphibia. Gebrüeder Borntraeger, Berlim, $241 \mathrm{pp}$.

King M and Rofe R (1976) Karyotype variation in the Australian gekko Phyllodactylus marmoratus (Gray) (Gekkonidae, Reptilia). Chromosoma 54:75-87.

Kuramoto M (1990) A list of chromosome numbers of anuran amphibians. Bull Fukuoka Univ Educ 39:83-127.

Lötters S, Haas W, Schick S and Böhme W (2002) On the systematics of the harlequin frogs (Amphibia, Bufonidae, Atelopus) from Amazonia. II. Redescription of Atelopus pulcher (Boulenger, 1882) from the eastern Andean versant in Peru. Salamandra 38:165-184.

Lötters S, van der Meijden A, Rödder D, Koester TE, Kraus T, La Marca E, Haddad CFB and Veith M (2010) Reinforcing and expanding the predictions of the disturbance vicariance hypothesis in Amazonian harlequin frogs: A molecular phylogenetic and climate envelope modeling approach. Biodivers Conserv 19:2125-2146.

Lourenço LB, Nascimento JAA, Andrade GV, Rossa-Feres DC and Recco-Pimentel SM (2006) Chromosomal analysis of the leptodactylids Pleurodema diplolistris and Physalaemus nattereri (Amphibia, Anura). Amphibia-Reptilia 27:481489.

Medeiros LR, Rossa-Feres DC and Recco-Pimentel SM (2003) Chromosomal differentiation of Hyla nana and Hyla sanborni (Anura, Hylidae), with a description of NOR polymorphism in H. nana. J Hered 94:149-154.

Ramos CW, Pimentel N and Martínez-Cortés V (2002) Karyotype of the endemic golden frog Atelopus zeteki (Dunn) from Panama. Carib J Sci 38:268-270.
Schmid M (1978) Chromosome banding in Amphibia I. Constitutive heterochromatin and nucleolus organizers regions in Bufo and Hyla. Chromosoma 66:361-388.

Schmid M (1980) Chromosome banding in Amphibia IV. Diferentiation of GC and AT-rich chromosome regions in Anura. Chromosoma 77:83-103.

Siqueira S, Aguiar-Jr O, Strüssmann C, Del-Grande ML and Recco-Pimentel SM (2008) Chromosomal analysis of three Brazilian "eleutherodactyline" frogs (Anura, Terrarana), with suggestion of a new species. Zootaxa 1860:51-59.

Sumner AT (1972) A simple technique for demonstrating centromeric heterochromatin. Exp Cell Res 75:304-306.

Venable JH and Coggeshall R (1965) Simplified lead citrate strain for use in electron microscopy. J Cell Biol 25:407-408.

Veiga-Menoncello ACP, Lima AP and Recco-Pimentel SM (2006) Sperm morphology of five species of Colostethus (Anura Dendrobatidae) with phylogenetic comments. Acta Zool 87:147-157

Veiga-Menoncello AC, Aguiar-Jr O, Lima AP and Recco-Pimentel SM (2007) The biflagellate spermatozoa of Colostethus marchesianus (Melin 1941) (Anura Dendrobatidae) from the type locality and Colostethus sp (aff marchesianus) from a different locality: A scanning and transmission electron microscopy analysis. Zool Anz 246:49-59.

Watson ML (1958) Staining of tissues sections of electron microscopy with heavy metals. J Biophys Biochem Cytol 4:475478.

\section{Internet Resources}

Frost DR (2013) Amphibian species of the world: an online reference. Version 5.6 (9 January 2013). Electronic Database accessible at http://research.amnh.org/herpetology/amphibia/index.html. American Museum of Natural History, New York, USA (March, 2013).

Associate Editor: Yatiyo Yonenaga-Yassuda

License information: This is an open-access article distributed under the terms of the Creative Commons Attribution License, which permits unrestricted use, distribution, and reproduction in any medium, provided the original work is properly cited. 